\title{
Site-specific estimates of water yield applied in regional acid sensitivity surveys across western Canada
}

\author{
John J. GIBSON*, S. Jean BIRKS ${ }^{1)}$, Dean S. JEFFRIES ${ }^{2)}$, Sanjeev KUMAR, Kenneth A. SCOTT ${ }^{3)}$, \\ Julian AHERNE ${ }^{4)}$ and D. Patrick SHAW ${ }^{5}$ \\ Department of Geography, University of Victoria, Victoria, BC V8W 3P5, Canada \\ Alberta Research Council, Victoria, BC V8Z 7X8, Canada \\ ${ }^{1)}$ Alberta Research Council, Calgary, AB T2L 2A6, Canada \\ ${ }^{2}$ Environment Canada, National Water Research Institute, Burlington, ON L7R 4A6, Canada \\ ${ }^{3)}$ Saskatchewan Environment, Regina, SK S4S 5W6, Canada \\ ${ }^{4)}$ Environmental and Resources Studies, Trent University, Peterborough, ON K9J 7B8, Canada \\ ${ }^{5)}$ Environment Canada, Pacific and Yukon Region, Vancouver, BC V6C 3S5, Canada \\ *e-mail corresponding author: jjgibson@uvic.ca
}

\begin{abstract}
Runoff or water yield is an important input to the Steady-State Water Chemistry (SSWC) model for estimating critical loads of acidity. Herein, we present site-specific water yield estimates for a large number of lakes (779) across three provinces of western Canada (Manitoba, Saskatchewan, and British Columbia) using an isotope mass balance (IMB) approach. We explore the impact of applying site-specific hydrology as compared to use of regional runoff estimates derived from gridded datasets in assessing critical loads of acidity to these lakes. In general, the average water yield derived from IMB is similar to the long-term average runoff; however, IMB results suggest a much larger range in hydrological settings of the lakes, attributed to spatial heterogeneity in watershed characteristics and landcover. The comparison of critical loads estimates from the two methods suggests that use of average regional runoff data in the SSWC model may overestimate critical loads for the majority of lakes due to systematic skewness in the actual runoff distributions. Implications for use of site-specific hydrology in regional critical loads assessments across western Canada are discussed.
\end{abstract}

Key words: Water yield, runoff, stable isotopes, lakes, acid sensitivity, Canada

\section{INTRODUCTION}

Acidification of surface waters has been a longstanding concern in rapidly developing areas of the world, including eastern Canada (Dillon et al. 1978; Henriksen et al. 1995), although relatively little attention has been given to acidification of lakes in western Canada until recently. Rapid expansion in oil sands mining in Alberta, growth in population, and increases in coastal marine traffic in southwestern British Columbia have created new concern for acid emissions and deposition in the western provinces (e.g., Tansey et al. 2002). Previous studies have suggested that lakes and ponds in western Canada may be sensitive to acidification due to prevalence of acid-sensitive soils (Weins 1987; Environment Canada 2004). A series of recent lake surveys in Manitoba (MB), Saskatchewan (SK), Alberta (AB), and British Columbia (BC) have been conducted to gain a more comprehensive baseline perspective on acid sensitivity in the region using a critical loads approach. The concept of critical loads, representing a threshold for atmospherically deposited $\mathrm{S}$ and $\mathrm{N}$ required to maintain the long-term chemical condition of a targeted ecosystem, was developed to design strategies for reducing regional and international air pollution (Nilsson \& Grennfelt 1988).
This paper presents and discusses site-specific hydrologic analyses that were conducted as part of these surveys in MB, SK and BC (Jeffries et al. 2010, this issue; Scott et al. 2010, this issue). Application of a similar approach to lakes in Alberta for a period of seven years has been discussed separately (Gibson et al. 2010, this issue, see also Bennett et al. 2008).

During a recent workshop on "Acid Deposition Critical Loads: Status of Methods and Indicators" organized by the Canadian Council of Ministers of the Environment (March 2009, Ottawa, Canada), scientists were unanimous in their view that the approach of determining critical loads continues to be a useful tool for assessing the sensitivity of an ecosystem to acid deposition and to inform emission reduction policies. More importantly, there was agreement that the next phase for improving these assessments be focused on improving the quality of input information to the existing critical load models. At present, the Steady-State Water Chemistry (SSWC) model is being used to estimate critical loads of acidity ( $\mathrm{S}$ and $\mathrm{N}$ ) for Canadian lakes (Henriksen et al. 2002).

One suggested improvement to application of the SSWC in regional lake surveys is use of site-specific hydrology, to better constrain the provincial or regional critical loads (Jeffries \& Ouimet 2005). Typically 


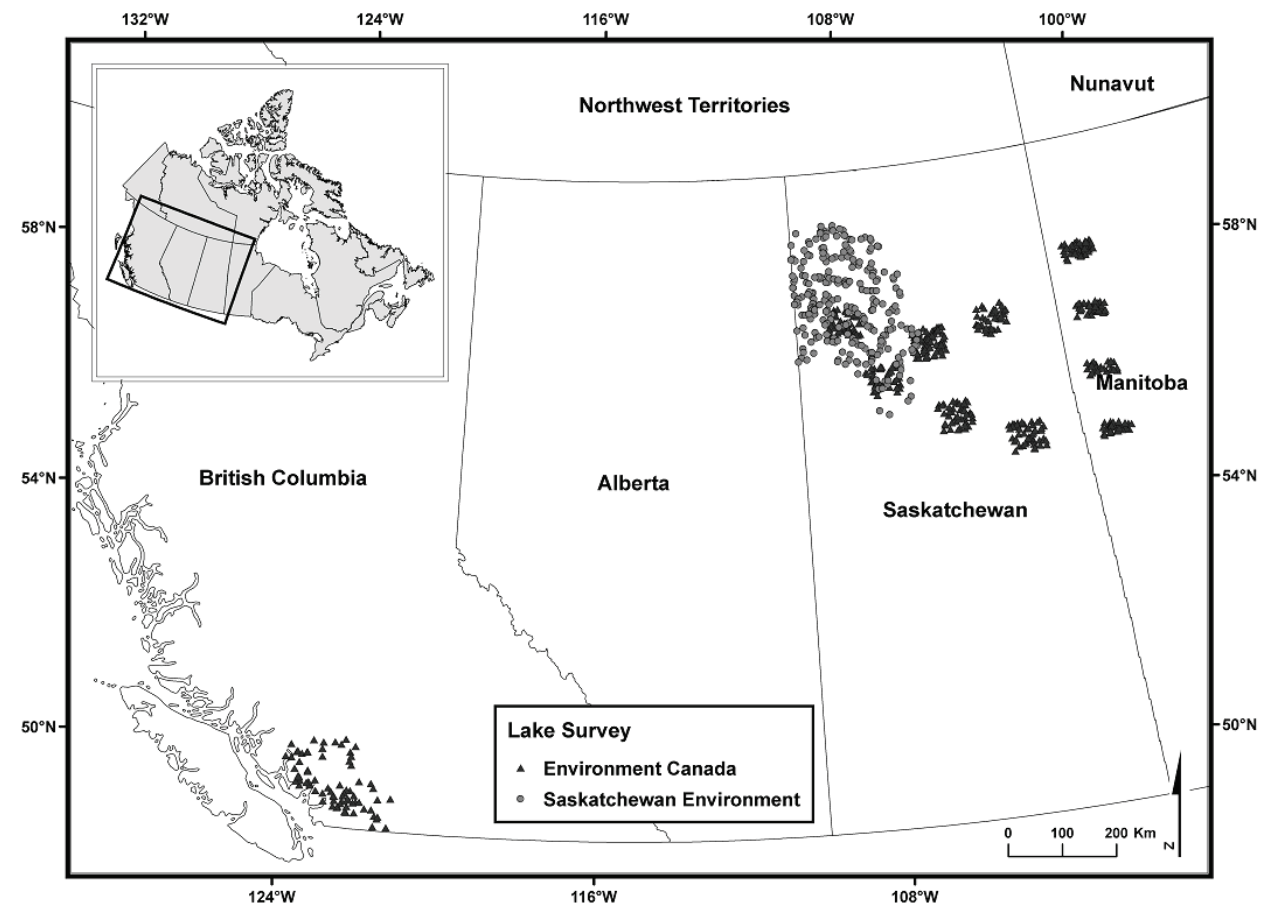

Fig. 1. Location of the western Canada lake surveys: Manitoba, Saskatchewan, and BC surveys by Environment Canada during 2006, 2007, and 2008 respectively (triangles); Saskatchewan survey by Saskatchewan Environment in 2007 and 2008 (circles). Inset shows location within Canada.

chemistry is site-specific, that is, it is based on water sampling in the lake of interest. But runoff or water yield has commonly been estimated from regional datasets, either applying regional runoff estimates based on hydrometric gauging or using climate-based indicators of runoff potential, such as precipitation (P) minus evapotranspiration (ET) (or P-ET). Due to a large complexity and heterogeneity of runoff behaviour on the regional scale (e.g., Silvapalan 2003), site-specific hydrology is expected to differ from estimates based on interpolation of regional runoff. While some advances have been made in runoff prediction in Boreal regions using the hydrological response unit approach to account for landscape effects (e.g., Devito et al. 2005), the data processing required precludes regional application at the present time.

Use of site-specific hydrology in application of the SSWC has not been extensively tested in Canada or worldwide due to limitations with modelling as described above, and also due to more fundamental practical issues associated with establishing hydrometric gauging stations in a large number of lakes. Here we examine use of an isotope mass balance (IMB) method developed by Gibson et al. (2002) and previously applied by Bennett et al. (2008) to estimate site-specific water yield (assumed to be equal to runoff) for critical loads assessment in a large number of lakes across western Canada. Similar to water chemistry, IMB is site-specific, as it is based on analysis of naturallyoccurring stable isotopes of water $\left(\delta^{18} \mathrm{O}\right.$ and $\left.\delta^{2} \mathrm{H}\right)$ in the lake of interest. The stable isotopes, which undergo systematic enrichment due to kinetic fractionation during evaporation, are measured using isotope ratio mass spectrometry, and evaluated in comparison to regional and global precipitation-isotope datasets as an insitu record of lake flushing rates and water yield to the lake. As such IMB is expected to capture hydrologic variability related both to macroscale climate forcings, but also, and importantly, due to heterogeneities in water routing, storage and runoff processes that accompany complex landscape/watershed patterns. The later are often difficult to characterize for lakes in western Canada, particularly by interpolation from regional runoff datasets, as discussed by Bennett et al. (2008).

The present study aims to demonstrate the application of the IMB to estimate water yield $\left(W_{Y}\right)$, to compare these estimates with a regional runoff dataset, to explore the implications of using site-specific hydrology for critical load estimates, and to discuss potential errors and limitations of the method. Despite being a first-order approach, the method is practical and field-based, and as we illustrate, offers a new and significantly sharper focus on hydrology and critical loads of acidity in regional lake surveys.

\section{MATERIAL AND METHODS}

\subsection{Sample collection and isotopic measurements}

Water samples were collected from lakes across $\mathrm{MB}, \mathrm{SK}$, and $\mathrm{BC}$ during a series of surveys conducted between 2006 and 2008 (Fig. 1). The surveys were conducted during late summer or fall (September-October) 
of respective sampling years. Environment Canada sampled 151 lakes from four geographic windows in northwestern MB in 2006 and 295 lakes from six windows in north-central SK in 2007. Lakes were selected by Environment Canada using a stratified-random selection design similar to that employed by Henriksen et al. (1996). This method resulted in a relatively higher proportion of small lakes in its sample population. An additional 262 lakes situated in northwestern SK were sampled by Saskatchewan Environment in 2007 and 2008 (Fig. 1). While this survey specifically targeted small headwater lakes, several larger headwater (11) and non-headwater lakes (3) were also included. Lakes $<1 \mathrm{~m}$ depth, or showing extensive macrophyte cover less than the air were rejected. The BC survey, conducted in 2008 by Environment Canada used a similar selective approach, included 74 lakes in the southwestern region of the province (Fig. 1). During the surveys, unfiltered water from each lake was collected in tightly-sealed high-density polyethylene bottles and returned for laboratory analysis of $\delta^{18} \mathrm{O}$ and $\delta^{2} \mathrm{H}$. All isotope results are given in $\delta$ notation in per mil (\%) relative to Vienna Standard Mean Ocean Water (VSMOW) (Coplen 1996). Standard deviation of measurements, in general, was $\pm 0.1 \%$ for $\delta^{18} \mathrm{O}$ and $\pm 0.4 \%$ o for $\delta^{2} \mathrm{H}$, with the exception of the 2008 SK samples, for which standard deviations were slightly higher for $\delta^{18} \mathrm{O}( \pm 0.4 \%)$ attributed to higher uncertainty in a single laboratory run.

\subsection{Isotope Mass Balance (IMB) method}

$W_{Y}$ estimates were generated using the IMB model developed under the assumptions of complete vertical mixing, constant density of water and steady-state conditions, shown to be a reasonable first-approximation for shallow lakes (Gibson et al. 2002; Bennett et al. 2008). $W_{Y}$ is assumed to be equal to the runoff derived from the land surface of the watershed which drains to each lake. Basically, the IMB model determines flushing rates for each lake from the degree of offset between measured isotopic composition of lake water and estimated isotopic composition of precipitation at each site. Subsequently, it calculates the inflow volume to the lake and partitions the inflow volume into vertical components of precipitation on the lake and lateral runoff. Runoff is then normalized to catchment area to estimate the depth-equivalent runoff or water yield $\left(W_{Y}\right)$. The theoretical basis of this model is explained further below.

In hydrologic and isotopic steady-state, water and isotope balances for a typical lake on an annual basis, are expressed, respectively as:

$$
\begin{array}{cl}
I=Q+E \quad\left(m^{3} \cdot y^{-1}\right) \\
I \delta_{I}=Q \delta_{Q}+E \delta_{E} & \left(\% 0 \cdot m^{3} \cdot y^{-1}\right)
\end{array}
$$

where $I, Q$ and $E$ are lake inflow, outflow and evaporation rates $\left(m^{3} \cdot y^{-1}\right)$, and $\delta_{I}, \delta_{Q}$ and $\delta_{E}$ are the isotopic compositions of inflow, discharge and evaporation fluxes (\%o), respectively. Rearranging eqn (2), and substituting $Q=I-E$ from eqn (1) we obtain:

$$
x=\frac{E}{I}=\frac{\left(\delta_{I}-\delta_{Q}\right)}{\left(\delta_{E}-\delta_{Q}\right)} \quad \text { (unitless) }
$$

where $E / I$ is the isotope-based evaporation to inflow ratio, also known as the flushing index, hereafter called $x$. Provided isotopic compositions on the right hand side of eqn (3) can be directly sampled or estimated, isotopic signatures can be used to quantify the flushing index $x$. For well-mixed lakes fed predominantly by precipitation sources, it can be assumed that $\delta_{Q}=\delta_{L}$ and $\delta_{I}=\delta_{P}$, i.e., the isotopic composition of discharge $\delta_{Q}$ is equivalent to that of lake water $\delta_{L}$, and that the isotopic composition of inflow $\delta_{I}$, to a first-order approximation, is equivalent to that of precipitation $\delta_{P}$, respectively. The isotopic composition of evaporate $\delta_{E}$ can be estimated using the well-known Craig-Gordon model, given in simplified form by Gat (1995) as:

$$
\delta_{E}=\left(\alpha^{*} \delta_{L}-h \delta_{A}-\varepsilon\right) /\left(1-h+10^{-3} \cdot \varepsilon_{K}\right) \quad(\%)
$$

where $\alpha^{*}$ is the equilibrium isotopic fractionation, $h$ is the humidity, $\delta_{A}$ is the isotopic composition of atmospheric moisture, and $\varepsilon=\varepsilon^{*}+\varepsilon_{K}$ is the total isotopic separation, comprised of the equilibrium $\varepsilon^{*}$ and kinetic $\varepsilon_{K}$ separations. The latter have been quantified for operational use from a range of laboratory and field experiments (Horita et al. 2008). Substitution of $\delta_{E}$ into eqn (3) yields:

$$
x=\frac{\left(\delta_{L}-\delta_{P}\right)}{m\left(\delta^{*}-\delta_{L}\right)} \quad \text { (unitless) }
$$

where $\quad m=\left(h-10^{-3} \cdot \varepsilon\right) /\left(1-h+10^{-3} \cdot \varepsilon_{K}\right) \quad$ and $\delta^{*}=\left(h \delta_{A}+\varepsilon\right) /\left(h-10^{-3} \cdot \varepsilon\right)$ as defined in Gibson (2002a). Eqn (5) is initially computed separately for each tracer, $\delta^{18} O$ and $\delta^{2} H$. While several different approaches have been used in previous investigations to estimate $\delta_{A}$, ranging from continuous vapour sampling to precipitation-humidity equilibrium, we resolve $\delta_{A}$ by an optimization method that effectively begins with the equilibrium assumption (i.e., $\delta_{A}=\delta_{P}-k \varepsilon^{*} ; k=1$ ) and then iteratively adjust $k$ to obtain a best-fit match for $\delta^{18} O$ and $\delta^{2} H$ results, essentially by best-fitting $k$ to the observed local evaporation line for each survey (see Bennett et al. 2008; Gibson et al. 2008). For this reason only a single isotope-based $x$ and $W_{Y}$, which integrate and are consistent regionally with both $\delta^{18} O$ and $\delta^{2} H$ signals, are reported for each lake.

As the inflow of the lake is comprised of precipitation on the lake surface as well as surface/groundwater runoff, i.e., $I=P+R$, we can estimate $R$ by substitution in eqn (3): 


$$
R=\frac{E}{x}-P \quad\left(m^{3} \cdot y^{-1}\right)
$$

where $E=e \cdot L A$ and $P=p \cdot L A, p$ and representing the annual depth-equivalent of evaporation and precipitation $\left(m \cdot y^{-1}\right)$, and $L A$ being the lake area $\left(m^{2}\right)$.

The annual water yield $W_{Y}$ (a.k.a. mean depthequivalent runoff) is then calculated from:

$$
W_{Y}=R \cdot D B A^{-1} \quad\left(m \cdot y^{-1}\right)
$$

where $D B A$ is the drainage basin area. Note that drainage basin area and lake area, which combine to form the watershed area, i.e., $W A=D B A+L A$, and are needed to estimate the volumes of precipitation and evaporation in eqn (6), are therefore prerequisite to estimation of $W_{Y}$.

\subsubsection{Limitations and uncertainty of IMB method}

Overall, the IMB should be regarded as a first-order approximation technique for site-specific water balance, and caution should therefore be used when interpreting results in terms of the long-term response of individual lakes. Note that Gibson et al. (2010, this issue) present a multi-year record of water yield variability in lakes that depicts the additional uncertainty that may arise from temporal variability when defining long-term response using the IMB.

It is important to note the following assumptions which are made to compute the IMB for the various lake surveys: (i) biologically-mediated vapour loss (i.e. transpiration) is not isotope fractionating, as is expected and commonly assumed (see Gat 1996), (ii) the isotopic composition of catchment water yield is close to that of precipitation (i.e., $\delta_{\mathrm{WY}}=\delta_{\mathrm{P}}$ ), as would be expected where runoff is locally derived from recent meteoric water that has not undergone substantial isotopic enrichment, and (iii) the lakes are well-mixed in late fall such that isotopic composition of discharge can be adequately characterized by representative sampling of lake water, $\delta_{\mathrm{L}}$, at this time. Grab sampling of water from the epilimnion of boreal lakes during the period of study has been shown to be a representative proxy for whole-lake water sampling (Gibson et al. 2002). However, at the time of sampling, several of the high elevation lakes in British Columbia had not overturned. As stratification during evaporation is expected to lead to preferential enrichment of heavy isotopes in the epilimnion, the net impact of our strategy is likely to have been overestimation of net enrichment for the whole water body and hence, underestimation of water yield. Despite this apparent limitation, net enrichment was found to be minor for $\mathrm{BC}$ lakes, and in some cases not significantly offset from the meteoric water line. Further discussion of these assumptions and justification for use in regional surveys is given by Gibson et al. (2002). In general, the ability of the IMB to capture hydrological variability among lakes is the most elucidating aspect of the analysis. By using standard precipitation and evaporation datasets to scale the IMB we ensure that similar average values are obtained with grid-based runoff dataset, with the result being an enhanced perspective of water yield variability and, in turn, critical loads distribution.

\subsection{Data collection}

Watershed parameters: Application of the IMB model requires delineation of the watershed areas, lake areas, and lake elevations for each of the study lakes. Information on the lake areas and lake elevations were provided by Saskatchewan Environment and Environment Canada for their respective surveys. All other information was determined using Geographic Information Systems (GIS).

Using the coordinates (latitude, longitude) for each lake, watershed area, lake area, and lake elevation were obtained using digital elevation data in raster format, corresponding to the 1: 50K NTS map sheets. National Hydro Network data in vector format were obtained from the GeoBase portal (www.geobase.ca). Terrain pre-processing was required before the Digital Elevation Model (DEM) was used for efficient watershed delineation. The hydrology network pre-processing stage involved DEM reconditioning as well as filling of small sinks. Assuming that the linear hydrographic data were more reliable than the elevation grid, the DEM was reconditioned to modify the original elevation data by imposing the vector hydrographic network onto it. The sinks in the grid were filled so that water could flow across the landscape without being trapped in depressions. For each cell in a grid the flow to the nearest neighbour along one of eight main compass directions was computed. The flow accumulation grid that contains the accumulated number of cells upstream of a particular cell was also calculated. In the following step, a grid of streams was created based on the threshold value of flow accumulation. Finally, the catchment grid delineation, catchment polygon processing, drainage line processing, adjoining catchment processing, and drainage point processing functions were run to obtain additional layers that describe the drainage patterns in the study area.

Individual watersheds were delineated in the ArcGIS program using the ArcHydro tools where each watershed was delineated upstream of a lake outlet. Hydrographic and elevation datasets were used to depict the lake outlet locations. In some cases two or more partial watersheds had to be merged together to create a final watershed polygon feature. The planimetric area of both the lake and watershed polygons was calculated in the ArcGIS program based on the equal area projection. The elevation value at locations where the lakes were sampled was extracted from the DEM using the Extract Values to Points tool.

Climate parameters: The climatological parameters (precipitation, relative humidity, surface evaporation, and temperature) required to run the IMB model were 
obtained from the North American Regional Reanalysis (NARR) dataset (Mesinger et al. 2006). The NARR dataset is a long-term, dynamically consistent, highresolution, high-frequency, atmospheric and land surface hydrology dataset for the North American domain. This model dataset has a horizontal resolution of $32 \mathrm{~km}$ and 45 vertical layers providing a much higher resolution than the global reanalysis datasets.

Climatological average monthly fields (based on data from 1979-2003) were extracted for the grid cells corresponding to the location of each of the study lakes. The parameters extracted were (i) APCPsfc: surface total precipitation $\left(\mathrm{kg} \mathrm{m}^{-2}\right.$ ), (ii) $\mathrm{RH} 2 \mathrm{~m}: 2 \mathrm{~m}$ relative humidity (\%), (iii) EVPsfc: surface evaporation ( $\mathrm{kg}$ $\mathrm{m}^{-2}$ ), (iv) TMP2 $\mathrm{m}: 2 \mathrm{~m}$ temperature (K).

The evaporation flux-weighting approach developed by Gibson (2002b) was used to flux-weight estimates for relative humidity and temperature so that the water balance calculations are representative of the open water season. For example, the evaporation flux-weighted estimates for $2 \mathrm{~m}$ temperature over the period covered by $\mathrm{n}$ months is given below as the sum of the temperature $(T)$ multiplied by the evaporation $(E)$ for each month divided by the sum of the total evaporation over the $\mathrm{n}$ months:

$$
T_{F W}=\frac{\sum_{i=1}^{n} E_{i} T_{i}}{\sum_{i=1}^{n} E_{i}}
$$

The same evaporation flux-weighting was performed for relative humidity. Isotopic parameters: Monthly precipitation $\delta^{18} \mathrm{O}$ estimates were obtained for each lake location based on empirically derived relationships between latitude and elevation (Bowen \& Wilkinson 2002). The $\delta^{2} \mathrm{H}$ composition of monthly precipitation was calculated assuming that precipitation would follow the relationship defined by the Global Meteoric Water Line (GMWL; Craig 1961). Similar to flux-weighted temperature and relative humidity values, annual averages of precipitation isotope fields were amountweighted using monthly precipitation amount estimates obtained from the NARR dataset. The amount-weighted annual averages of precipitation isotope compositions were determined by multiplying the amount of precipitation (P) for each month by the estimated isotopic composition of precipitation for that month $(\delta)$ and dividing by the sum of precipitation over that time period (n months). These calculations were performed using long-term average climatologies of these parameters.

Regional runoff estimates: The following steps were taken to obtain long-term average runoff estimates for the region. First of all, long-term (1961-1990) average monthly temperature, precipitation, and cloudiness were derived from a $0.5^{\circ} \times 0.5^{\circ}$ resolution global database (New et al. 2000). Evapotranspiration was calculated with a sub-model used in the IMAGE global change model (Leemans \& Van den Born 1994) following the approach of Prentice et al. (1993). Potential evapotranspiration was computed from temperature, sunshine, and latitude. The effect of snow cover on evapotranspiration was included by simulating accumulation and melting of a snow layer at each site using temperature and precipitation. Actual evapotranspiration was then computed using a reduction function for potential evapotranspiration described by Federer (1982). Runoff, estimated assuming runoff equal precipitation minus actual evapotranspiration, were subsequently interpolated to the Global Environmental Multiscale (GEM) grid at a resolution of $35 \mathrm{~km} \times 35 \mathrm{~km}$.

Critical load estimation: A first approximation of critical acid loads $\left(C L_{A}\right)$ during the present study was performed using the SSWC model (Henriksen et al. 1992, 2002). The calculations were performed using two different approximations of $W_{Y}$ : runoff estimates interpolated from a 0.5 degree grid and the IMB derived $W_{Y}$ estimates. In the critical loads equation, $W_{Y}\left(\mathrm{~m} y^{-1}\right)$ is used to represent the annual average net catchment runoff, according to:

$$
\begin{gathered}
C L_{A}=\left([B C]_{0}-\left[A N C_{\text {lim }}\right]\right) \cdot W_{Y} \\
\left(m e q \cdot m^{-2} \cdot y^{-1} \text { or } e q \cdot h a^{-1} \cdot y^{-1}\right)
\end{gathered}
$$

where $[\mathrm{BC}]_{0}$ is the pre-industrial non-marine flux of base cation concentrations assumed to be equivalent to the sum of base cations in present-day lake water, and $\mathrm{ANC}_{\text {lim }}$ is the critical acid-neutralizing capacity limit chosen to correspond to a threshold of protection for an ecosystem or individual species.

\section{RESULTS}

\subsection{Isotope characteristics}

Isotopic data obtained from the three regional surveys are shown in figure 2. In general, isotopic results from the Environment Canada survey in MB and SK fall along Local Evaporation Lines (LEL) characterized by systematic offset to the right of the meteoric water line, and indicating variable evaporative enrichment in these lake groups. The two LELs differ slightly in their slope and degree of scatter (Equations for LEL shown in Fig. 2). Lake waters collected from the SK survey (Saskatchewan Environment) also cluster along a LEL and are distinct from the GMWL (Craig 1961). Data from this survey differ slightly in the degree of scatter around the LEL from year to year (2007 and 2008), which is attributed to higher analytical uncertainty in $\delta^{18} \mathrm{O}$ for 2008. Despite this apparent issue, the overall slopes of the LEL for both years during this survey are very similar and are consistent with observations from adjacent regions of the northeast (NE) Alberta (Bennett et al. 2008). The lake waters from $\mathrm{BC}$ fall in a cluster on or slightly below the Local Meteoric Water Line (LMWL) for Revelstoke (Sinclair 2009), and close to the GMWL (Craig 1961). The isotopic composition of lakes in the $\mathrm{BC}$ survey indicates very little evaporative 


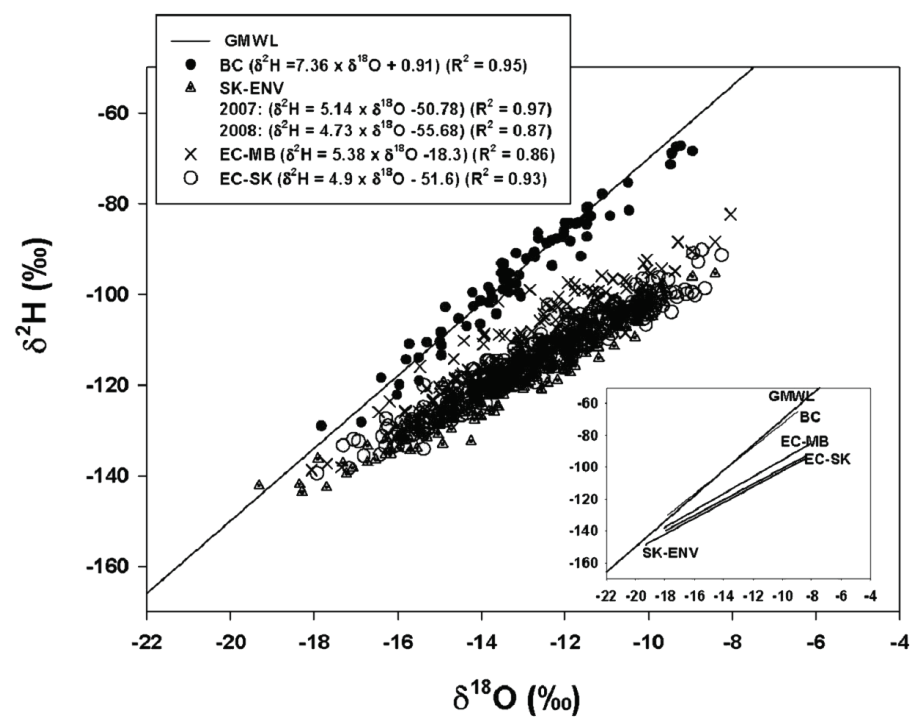

Fig. 2. $\delta^{2} \mathrm{H}-\delta^{18} \mathrm{O}$ plot of all the lakes surveyed during the study period. Legend: $\mathrm{BC}-$ British Columbia lakes surveyed by Environment Canada, SK-ENV - Saskatchewan lakes surveyed by Saskatchewan Environment, EC-SK - Saskatchewan lakes surveyed by Environment Canada, EC-MB - Manitoba lakes surveyed by Environment Canada. Trend lines and equations for LEL of each survey are shown in insets.

enrichment, plotting very close to the GMWL with a slope of 7.36 .

\subsection{IMB water yields}

The results of the IMB analysis for the different surveys along with a long-term gridded runoff dataset, based on P minus ET, are shown in figures 3 through 6 to illustrate the effect of using site-specific hydrology. Despite having similar average values, the site-specific estimates of $W_{Y}$ based on the IMB model are far more variable than the grid- based estimates, and commonly show skewed distributions (Figs 3-6). The somewhat different distributions for IMB runoff for the two surveys in SK (Fig. $4 \mathrm{~b}$ and $5 \mathrm{~b}$ ) probably reflects differences in lake selection methods. The Environment Canada lake selection was random within specified size classes resulting in a relatively higher proportion of small lakes in its sample population, many of which had very low $W_{Y}$ values. On the other hand, the Saskatchewan Environment survey had several larger lakes.

\section{DISCUSSION}

\subsection{Usefulness of IMB model and hydrological variability}

Accurate assessment of $W_{Y}$ to individual lakes is an important prerequisite to application of critical loads on a site-specific basis. While distributed hydrological modelling has thus far been unable to tackle the challenge of reproducing local hydrology in small systems, in part due to the heterogeneity of landscapes (Silvapan 2003), but also in Canada due to the broad expanses of remote, data-sparse regions, IMB offers a first-approximation method for constraining the local runoff response.
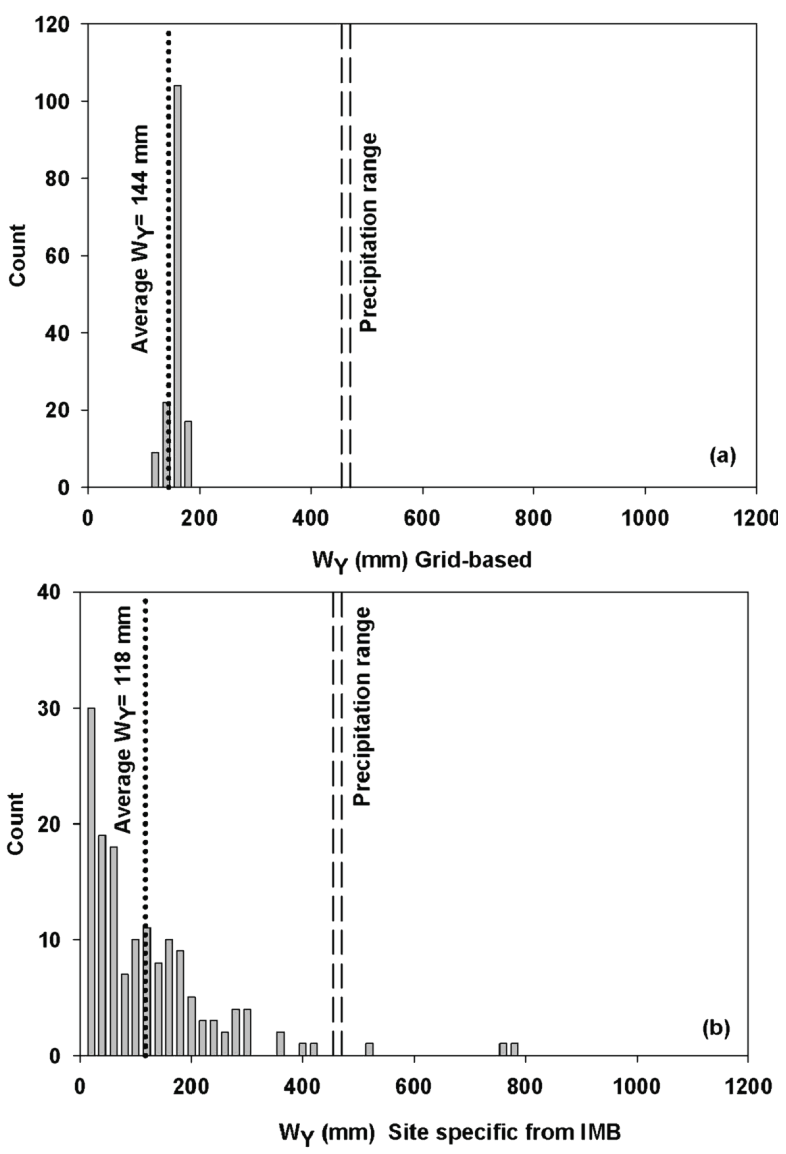

Fig. 3. Comparison of long-term average water yields calculated from (a) the long term average runoff estimates based on gridded climate fields and (b) site specific IMB assessments of hydrology for the Manitoba lakes (Environment Canada survey). The dashed band and the dotted line represent precipitation range and the average $W_{Y}$, respectively. 

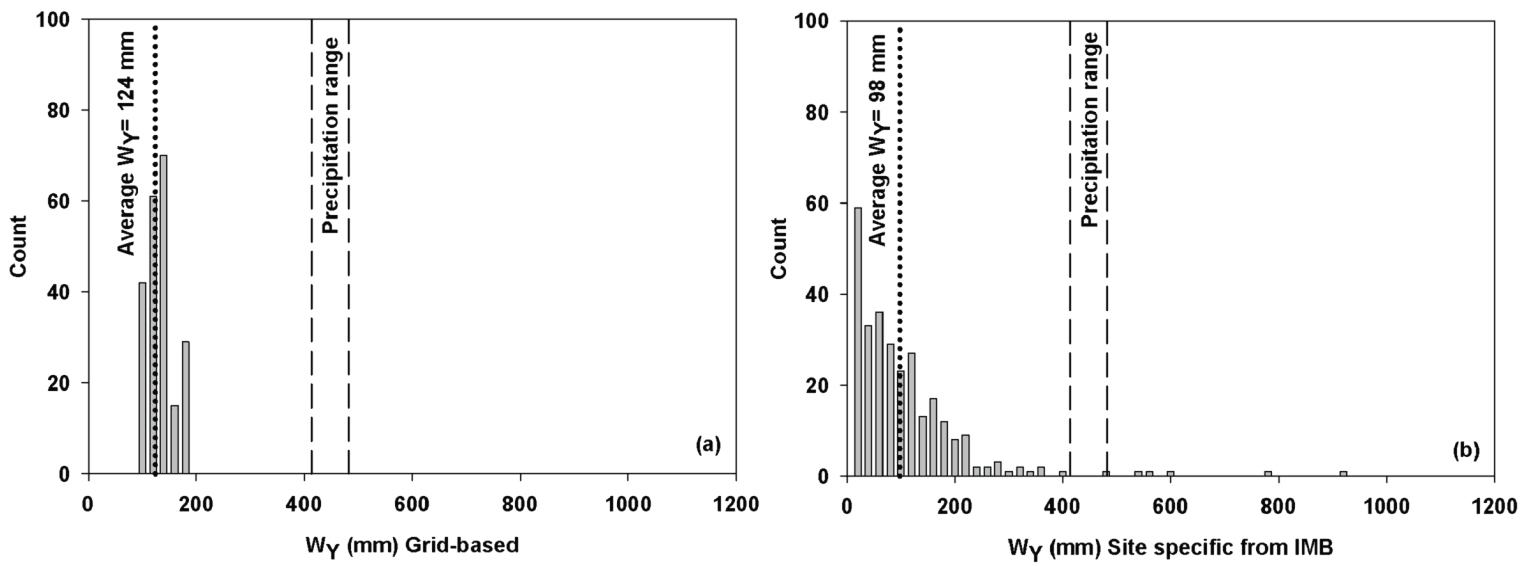

Fig. 4. Comparison of long-term average water yields calculated from (a) the long term average runoff estimates based on gridded climate fields and (b) site specific IMB assessments of hydrology for the Saskatchewan lakes (Environment Canada survey). The dashed band and the dotted line represent precipitation range and the average $W_{Y}$, respectively.
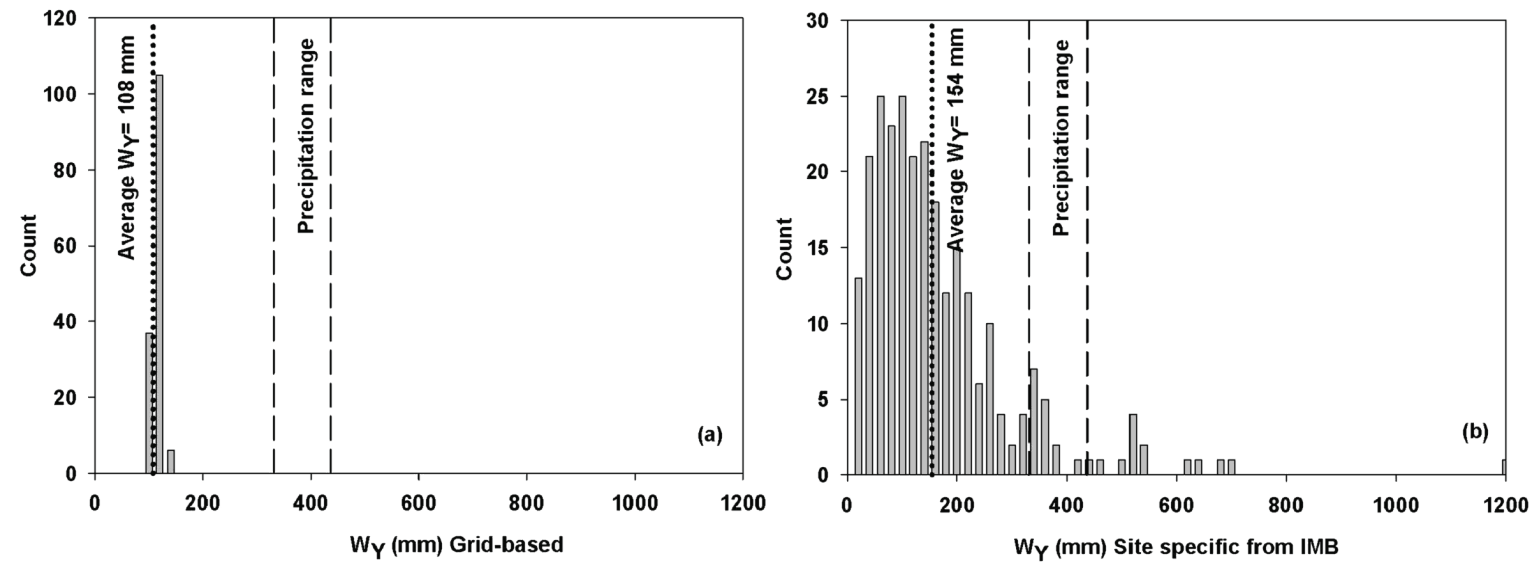

Fig. 5. Comparison of long-term average water yields calculated from (a) the long term average runoff estimates based on gridded climate fields and (b) site specific IMB assessments of hydrology for the Saskatchewan lakes (Saskatchewan Environment survey). The dashed band and the dotted line represent precipitation range and the average $W_{Y}$, respectively.
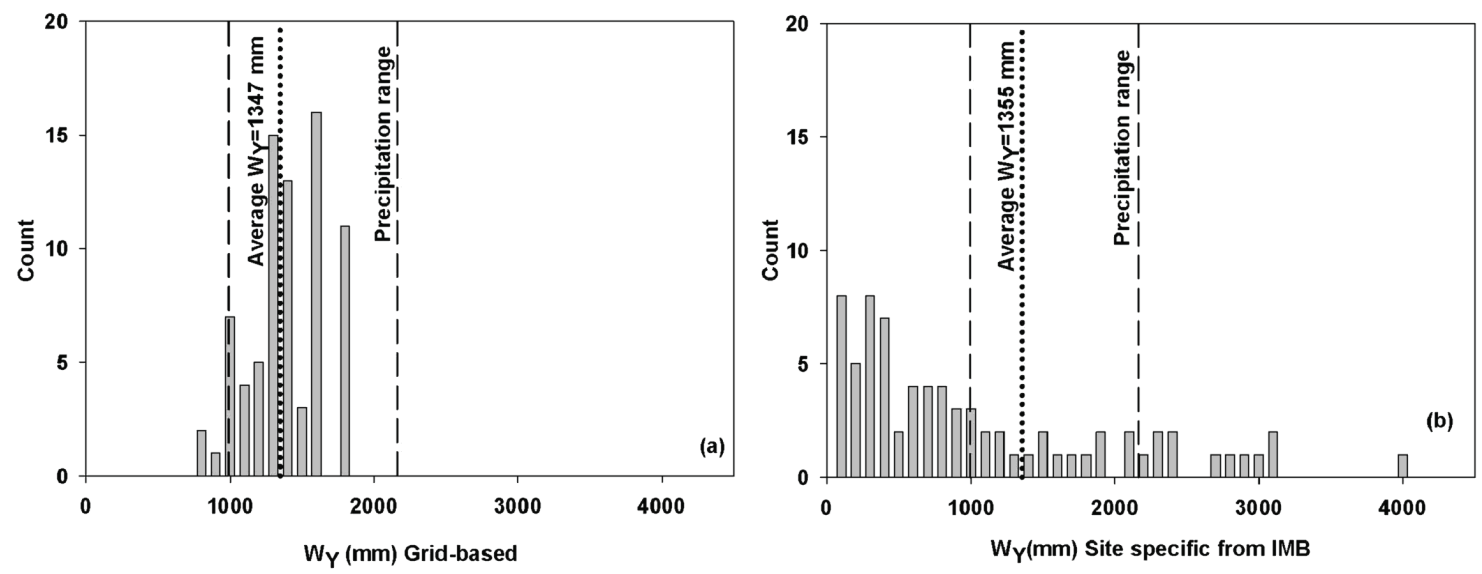

Fig. 6. Comparison of long-term average water yields calculated from the (a) long term average runoff estimates based on gridded climate fields and (b) site specific IMB assessments of hydrology for southwestern British Columbia (Environment Canada survey). The dashed band and the dotted line represent precipitation range and the average $W_{Y}$, respectively. 
The long-term average runoff datasets based on excess precipitation ( $\mathrm{P}$ minus $\mathrm{ET}$ ); while useful for inter-regional and global comparisons, do not fully capture water balance variations related to local watershed or landscape heterogeneity. This is an anticipated result that has been observed in well-instrumented watersheds, but one that has not previously been demonstrated on the scale of large regional surveys of 10 s or 100 s of lakes. The results of the IMB analysis strongly suggest that local factors play a defining role on lake water balance in western Canada, an observation made also by Devito et al. (2005) and others using hydrological response unit (HRU) approaches.

The distributions of $W_{Y}$ values from the lakes in all surveys are found to be skewed to lower water yield values (Figs 3 to 6), indicating a systematic organization of watersheds at the regional scale. While detailed analysis of land cover, gradients and other hydrographic controls has not yet been conducted, this skewness is likely due to systematic patterns in connectivity and lake order, whereby many low order lakes are more disconnected than average, with progressively fewer higher-order lakes gathering runoff, and only a few becoming the ultimate pathway or focus of regional runoff. Further studies will be required to assess whether the observed variability can be reconciled with land cover sufficiently to build an HRU capable of application in site-specific applications but this is beyond the scope of the current research.

The range in $W_{Y}$ estimates for the SK and MN surveys is in line with that found in NE Alberta (see Bennett et al. 2008; Gibson et al. 2010, this issue) with average values similar to the gridded runoff dataset (Figs 3-4). Also, the slopes of the LEL for both surveys are similar to that of NE Alberta (Bennett et al. 2008), with slightly steeper LEL in MB possibly due to the samples that appear to have very little enrichment, plotting just below the GMWL (Craig 1961).

Whereas in MB and SK, lakes plot on distinct LELs with slopes close to 5 (which is also observed for $\mathrm{AB}$; see Bennett et al. 2008; Gibson et al. 2010, this issue), the data from BC plot much closer to the GMWL, with a slope of 7.36. Also, quite a few samples from this survey have isotopic compositions above the GMWL and in some cases above reported LMWLs for southern BC. These results are reflective of the dominance of precipitation over evapotranspiration in the region. The lakes surveyed in $\mathrm{BC}$ therefore tend to retain much of the parent isotopic signal from the precipitation sources at each site, and variation in both isotope content of the lakes and derived water yield appears to be related more to the elevation gradient in incident precipitation.

In southwestern $\mathrm{BC}, W_{Y}$ estimates were within the expected range for the majority of lakes (63; Fig. 6). However, six of the lakes in the survey (not shown individually) had inferred precipitation compositions $\left(\delta_{\mathrm{P}}\right)$ that were more enriched than the measured lake compo- sition. This suggests that the runoff feeding the lake may have originated at a much higher elevation with a more negative $\delta^{18} \mathrm{O}$ and $\delta^{2} \mathrm{H}$ composition. The unrealistic enrichment of inferred local precipitation relative to lake water resulted in negative $W_{Y}$ estimates for these six lakes. For another two lakes (Lake 15 and Lake 17), $W_{Y}$ was an order of magnitude greater $(15,220 \mathrm{~mm}$ and $24,251 \mathrm{~mm}$, respectively) than the rest of the lakes in the survey, and much higher than runoff estimates for the region. Closer inspection of the hydrological settings for these two anomalous lakes reveals that they are both situated adjacent to areas of snowpack or glaciers. It is evident from the results that glacier melt is forming a significant component of their water budget and creating runoff volumes which are greater than precipitation on their respective watersheds.

\subsection{Implications for regional critical load estimation}

As noted earlier, the results presented here indicate that the average $W_{Y}$ 's based on the IMB and on the gridded runoff estimates based on $\mathrm{P}$ minus ET are remarkably similar. However, the runoff datasets, as they are primarily climate-driven, predict very little variation in hydrology among nearby lakes, whereas the site-specific $W_{Y}^{\prime}$ 's capture a larger, more representative range in hydrological settings (Figs 3-6). This fine-scale characterization of hydrological settings also has implications for the regional critical load estimation (Fig. 7). In general, $80 \%$ of lakes in these surveys (with the exception of the Saskatchewan Environment survey) have relatively lower critical loads when calculated using $W_{Y}$ from IMB approach compared to the gridded runoff estimates (Fig. 7). Different cumulative patterns for critical loads obtained from the Saskatchewan Environment survey (Fig. 7c) may be due to different sampling design for lake selection.

Overall, these new critical load estimates show that the sampled regions of MB and SK may be relatively more sensitive to acidic deposition than previously thought. For example, Jeffries \& Ouimet (2005) reported that provincial critical load for SK $\left(5^{\text {th }}\right.$ percentile value of all available provincial data) was 148 eq $\mathrm{ha}^{-1} \mathrm{y}^{-1}$ whereas the values determined here using IMB derived $W_{Y}$ are 6.8 eq ha ${ }^{-1} \mathrm{y}^{-1}$ (Environment Canada Survey) and 27.1 eq ha ${ }^{-1} \mathrm{y}^{-1}$ (Saskatchewan Environment). The provincial critical load using the long-term average runoff values during the present study are 53.3 eq ha ${ }^{-1} \mathrm{y}^{-1}$ and 58.7 eq ha $^{-1} \mathrm{y}^{-1}$ for Environment Canada and Saskatchewan Environment survey, respectively. Although the two studies (Jeffries \& Ouimet 2005 and the present study) may not be directly comparable, the difference between these two may be related to the influence of the new runoff estimates and small sample size for the earlier assessment. In fact, the data limitations placed on the Jeffries \& Ouimet (2005) analysis was the driving force behind conducting the new lake surveys discussed here, although the IMB approach for site-specific hydrology was developed separately. 

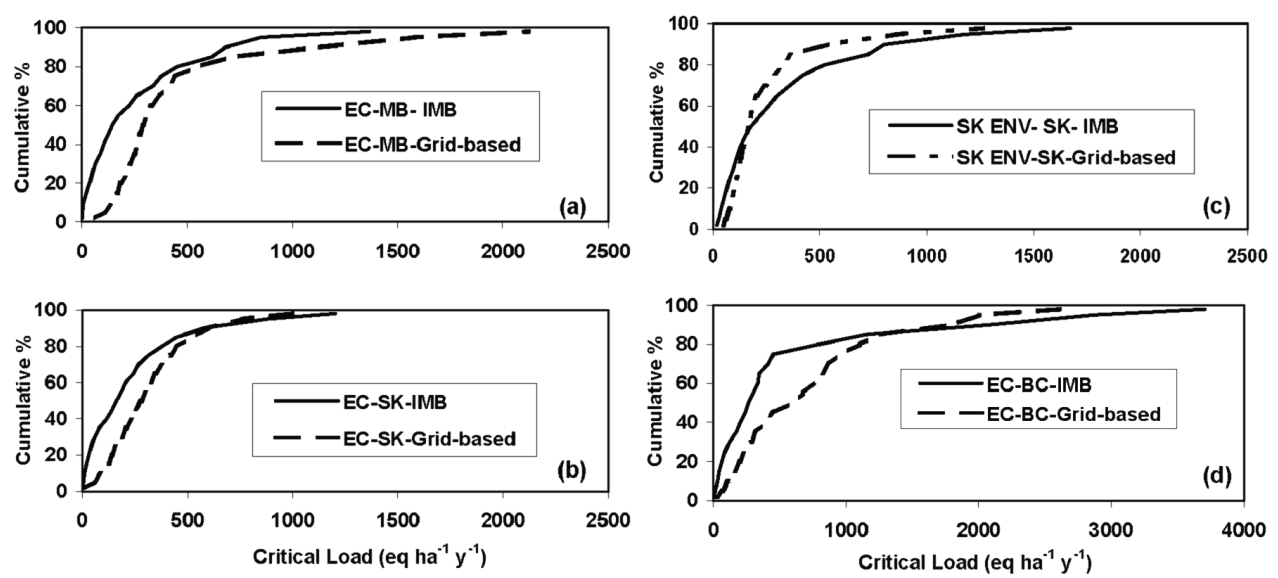

Fig. 7. Relationships between cumulative $\%$ of lakes and critical load calculated using water yield from IMB (Isotope $W_{Y}$ ) and long term average runoff estimates (Conventional $W_{Y}$ ) for (a) Manitoba lakes surveyed by Environment Canada, (b) Saskatchewan lakes surveyed by Environment Canada, (c) Saskatchewan lakes surveyed by Saskatchewan Environment and (d) British Columbia lakes surveyed by Environment Canada.

\subsection{Limitation of IMB model for western Canada}

Overall, it appears that the hydrological setting of a lake has a strong influence on water yield and in turn on the critical load estimates. As mentioned earlier, the IMB model is based on the assumption that the isotopic composition of $W_{Y}\left(\delta_{\mathrm{WY}}\right)$ to the lake can be approximated by the isotopic composition of precipitation $\left(\delta_{\mathrm{P}}\right)$. Given the low relief in the Canadian prairies, this assumption appears to be sufficient to capture variations in precipitation isotope labelling. However, the hydrological settings of the lakes in southwestern $\mathrm{BC}$ suggest that this assumption may not apply to all lakes. As described above, there are some lakes that appear to be receiving discharge from glaciers, which would have a different (more negative) isotopic composition of inputs. A significant component of glacial melt water as part of their water yield would violate the assumption that $\delta_{\mathrm{P}}$ can be approximated by the simple elevation altitude relationship defined by Bowen \& Wilkinson (2002). Fine-tuning of our hydrological assessment could be made by identifying the presence of glaciers in each of the lake watersheds. The southwestern BC lake survey was conducted over an area with very large catchment relief. The isotopic composition of precipitation, and inflow was calculated based on the elevation of the lake. However, it is likely that for many watersheds the upper reaches of the catchments may be collecting precipitation at a much higher elevation. Given the relationship between the isotopic composition of precipitation and the elevation at which it condenses, this may result in inferred $\delta_{\mathrm{P}}$ values that are more positive than the real catchment runoff. This could be better captured in our model by using maximum or average catchment elevations to calculate $\delta_{\mathrm{P}}$ as opposed to the lake elevation. Refinements could also be made by taking into account lake order to characterize the string-oflakes effect (see Gibson \& Edwards 2002). While these modifications may improve reality of the characterization for individual lakes, they are not expected to significantly change the overall distribution statistics for $W_{Y}$ or $C L_{A}$ obtained in this analysis.

\section{CONCLUSIONS}

The present study explores the hydrological variability among lakes across western Canada by estimating water yield using an IMB model and also investigates its implications for regional critical load estimates. Despite having some limitations in areas of high relief, the IMB model has been demonstrated to be a feasible first-approximation tool for capturing hydrological variability among lakes in a given region, which otherwise would be impractical to achieve by other site-specific, field-based methods. While average water yield derived from IMB is found to be similar to the long-term average runoff, the IMB method suggests a systematic water-yield skewness that significantly reduces the critical load estimates. As we have shown, the use of a single, representative water sample to characterize both chemical and hydrologic drivers of acidification in each lake is a novel concept potentially offering a significantly sharper focus on critical loads in regional surveys. Future work will focus on further constraining the assumptions and uncertainties in the isotopic approach, particularly the effect of stratification on water yield estimation, and searching for the underlying causes of local hydrologic variability to improve hydrologic prediction for wider study of ungauged areas of interest.

\section{ACKNOWLEDGEMENTS}

From ARC Victoria, we thank Martina Szabova and Kent Richardson for GIS and geomatics support, and Kevin Tattrie and Yi Yi for editorial assistance. We also thank Max Posch, Coordination Centre for Effects, The Netherlands for providing long-term runoff data. This research was partially supported by the Cumulative En- 
vironmental Management Association and NSERC Discovery and CRD Grants to John Gibson.

\section{REFERENCES}

Bennett, K.E., J.J. Gibson \& P.M. McEachern. 2008. Water yield estimates for critical loadings assessment: comparisons of gauging methods versus and isotopic approach. Can. J. Fish. Aquat. Sci., 65: 83-99.

Bowen, G.J. \& B. Wilkinson. 2002. Spatial distribution of $\delta^{18} \mathrm{O}$ in meteoric precipitation. Geology, 30: 315-318.

Coplen, T.B. 1996. New guidelines for reporting stable hydrogen, carbon, and oxygen isotope-ratio data. Geochim. Cosmochim. Acta, 60: 3359-3360.

Craig, H. 1961. Isotopic variations in meteoric waters. Science, 133: 1702-1703.

Devito, K., I. Creed, T. Gan, C. Mendoza, R. Petrone, U. Silins \& B. Smerdon. 2005. A framework for broad-scale classification of hydrologic response units on the Boreal Plain: is topography the last thing to consider? - Invited Review. Hydrol. Process., 19: 1705-1714.

Dillon, P.J., D.S. Jeffries, W. Snyder, R. Reid, N.D. Yan, D. Evans, J. Moss \& W.A. Scheider. 1978. Acidic precipitation in south-central Ontario: recent observations. J. Fish. Res. Board Can., 35: 809-815.

Environment Canada. 2004. Canadian acid deposition science assessment. Meteorological Service of Canada, Toronto, Ontario. www.msc-smc.ec.gc.ca/saib/acid/acid e.html.

Federer, C.A. 1982. Transpirational supply and demand: plant, soil and atmospheric effects evaluated by simulation. Wat. Resour. Res., 18: 355-362.

Gat, J.R. 1995. Stable isotopes of fresh and saline lakes. In: Lerman A., D. Imboden \& J. Gat (Eds), Physics and chemistry of lakes. Springer-Verlag: New York: 139-166.

Gat, J. R. 1996. Oxygen and hydrogen isotopes in the hydrological cycle. Ann. Rev. Earth. Planet. Sci., 24: 225-262.

Gibson, J.J. 2002a. Short-term evaporation and water budget comparisons in shallow arctic lakes using non-steady isotope mass balance. J. Hydrol., 264: 242-261.

Gibson, J.J. 2002b. A new conceptual model for predicting isotopic enrichment of lakes in seasonal climates. PAGES News, 10(2): 10-11.

Gibson, J.J. \& T.W.D. Edwards. 2002. Regional surface water balance and evaporation-transpiration partitioning from a stable isotope survey of lakes in northern Canada. Global Biogeochem. Cycles., 16(2): 10.1029/2001GB001839.

Gibson, J.J., E.E. Prepas \& P. McEachern. 2002. Quantitative comparison of lake throughflow, residency, and catchment runoff using stable isotopes: modeling and results from a regional survey of Boreal lakes. J. Hydrol., 262: 128-144.

Gibson, J.J., S.J. Birks \& T.W.D. Edwards. 2008. Global prediction of $\delta_{\mathrm{A}}$ and $\delta^{2} \mathrm{H}-\delta^{18} \mathrm{O}$ evaporation slopes for lakes and soil water accounting for seasonality. Global Biogeochem. Cyc., 22: GB2031, doi: 10.1029/2007GB002997.

Gibson, J.J., S.J. Birks, S. Kumar, P.M. McEachern \& R. Hazewinkel. 2010. Interannual variations in water yield to lakes in northeastern Alberta: implications for estimating critical loads of acidity. J. Limnol., 69(Suppl. 1): 126-134. DOI: $10.3274 / J L 10-69-S 1-13$.

Henriksen, A., P.J. Dillon \& J. Aherne. 2002. Critical loads of acidity for surface waters in south-central Ontario, Canada: regional application of the Steady-State Water Chemistry (SSWC) model. Can. J. Fish. Aquat. Sci., 59: 1287-1295.

Henriksen, A., J. Kamari, M. Posch \& A. Wilander. 1992. Critical loads of acidity: Nordic surface waters. Ambio, 21: 356-363.

Henriksen, A., M. Posch, H. Hultberg \& L. Lien. 1995. Critical loads of acidity for surface waters: can the ANClimit be considered variable? Water Air Soil Pollut., 85: 24192424 .
Henriksen, A., B.L. Skelkvåle, L. Lien, T.S. Traaen, J. Mannio, M. Forsius, J. Kämäri, I. Mäkinen, T. Berntell, T. Wiederholm, A. Wilander, T. Moiseenko, P. Lozovik, N. Filatov, R. Niinioja, R. Harriman \& J.P. Jensen. 1996. Regional lake surveys in Finland, Norway, Sweden, northern Kola, Russian Karelia, Scotland, Wales 1995: coordination and design. Acid Rain Research Report 40/1996, Norwegian Institute for Water Research, Oslo, Norway: $30 \mathrm{pp}$.

Horita, J., K. Rozanski \& S. Cohen. 2008. Isotope effects in the evaporation of water: a status report of the CraigGordon model. Isoto. Environ. Heal. Stud., 44: 23-49.

Jeffries, D.S. \& R. Ouimet (Eds). 2005. Chapter 8: Critical Loads - Are they being exceeded? In: 2004 Canadian acid deposition science assessment. Environment Canada, Ottawa, Ontario, 341-368.

Jeffries, D.S., R.G. Semkin, J.J. Gibson \& I. Wong, 2010. Recently surveyed lakes in northern Manitoba and Saskatchewan, Canada: characteristics and critical loads of acidity. J. Limnol., 69(Suppl. 1): 45-55. DOI: 10.3274/ JL10-69-S1-06

Leemans, R. \& G.J. Van den Born. 1994. Determining the potential distribution of vegetation, crops and agricultural productivity. Water Air Soil Pollut., 76: 133-161.

Lin, G. Manikin, D. Parrish \& W. Shi. 2006. North American Regional Reanalysis: A long-term, consistent, high-resolution climate dataset for the North American domain, as a major improvement upon the earlier global reanalysis datasets in both resolution and accuracy. Bull. Amer. Meteorol. Soc., 87: 343-360.

Mesinger F., G. DiMego, E. Kalnay, K. Mitchell, P. C. Shafran, W. Ebisuzaki, D. Jovic, J. Woollen, E. Rogers, E. H. Berbery, M. B. Ek, Y. Fan, R. Grumbine, W. Higgins, H. Li, Y. Lin, G. Manikin, D. Parrish \& W. Shi. 2006. North American Regional Reanalysis: A long-term, consistent, high-resolution climate dataset for the North American domain, as a major improvement upon the earlier global reanalysis datasets in both resolution and accuracy. Bull. Amer. Meteorol. Soc., 87: 343-360.

New, M., M. Hulme \& P.D. Jones. 2000. Representing twentieth century space-time climate variability. Part 2: Development of 1901-96 monthly grids of terrestrial surface climate. J. Climate, 13: 2218-2238.

Nilsson, J. \& P. Grennfelt (Eds). 1988. Critical loads for sulphur and nitrogen. Miljørapport 1988:15, NORD 1998:097, Nordic Council of Ministers, Copenhagen, Denmark: 418 pp.

Prentice, I.C., M.T. Sykes \& W. Cramer. 1993. A simulation model for the transient effects of climate change on forest landscapes. Ecol. Modell., 65: 51-70.

Scott, K.A., B. Wissel, J.J. Gibson \& S.J. Birks. 2010. Chemical characteristics and acid sensitivity of boreal headwater lakes in northwest Saskatchewan. J. Limnol., 69(Suppl. 1): 33-44. DOI: 10.3274/JL10-69-S1-05.

Sivapalan M. 2003. Prediction in ungauged basins: a grand challenge for theoretical hydrology-invited commentary. Hydrol. Process., 17: 3163-3170.

Sinclair, K.E. 2009. Stable isotope-vapour trajectory relationships in Rocky Mountain snow packs. Dept Geography, University of Calgary $\mathrm{PhD}$ thesis.

Tansey, J., J. Carmichael, R. VanWynsberghe \& J. Robinson. 2002. The future is not what it used to be: participatory integrated assessment in the Georgia Basin. Global Environ. Change., 12: 97-104.

Wiens, J. H. 1987. Sensitivity of western and northern Canada soils and geology to acidic input. British Columbia. Ministry of Environment and Parks, Technical Committee for the Long-Range Transport of Atmospheric Pollutants in Western and Northern Canada., Coordinating Committee on Soil and Geology Sensitivity Mapping (Canada). Victoria, B.C. 